\title{
Monitoring of a shallow cover tunnel driven under live railway tracks
}

\author{
D Mares North Strathfield Rail Underpass Alliance, Australia \\ E Nye Mott MacDonald Australia Pty Ltd, Australia
}

\begin{abstract}
A shallow cover tunnel was excavated under live railway tracks just south of North Strathfield Railway Station, Sydney. The single track North Strathfield Rail Underpass (NSRU) consists of two dive structures either end of a $148 \mathrm{~m}$ long shallow cover driven tunnel. The underpass is designed for diesel hauled freight trains up to $1.5 \mathrm{~km}$ in length. The tunnel excavation dimensions are $7 \mathrm{~m}$ in height and $9 \mathrm{~m}$ in width and has a horseshoe shaped profile with the ground cover varying between 2.5 to $3.5 \mathrm{~m}$ above the tunnel crown.

The ground is predominately Ashfield shale rock with either fill or highly weathered shale at or above the tunnel crown. Finite element (FE) analysis calculated the stresses in the synthetic fibre reinforced shotcrete lining and was also used to assist in predicting surface settlements. Apart for the initial steel canopy tubes, no other steel support is installed in the driven tunnel (a first for Australia and perhaps in the world for such a shallow cover tunnel under live railway tracks). A repeated grid pattern of thirty-five grouted $12 \mathrm{~m}$ long fibre glass dowels ensured tunnel face stability. The tunnel face was mapped daily. The $12 \mathrm{~m}$ long canopy tube arrays had a $3 \mathrm{~m}$ overlap and their installation was staggered relative to the $12 \mathrm{~m}$ long face dowels by $4.5 \mathrm{~m}$. The excavation/shotcrete support cycle advanced in 1, 1.3 or $1.5 \mathrm{~m}$ increments depending on the geology, shotcrete strength and the displacement monitoring data. In tunnel displacement, monitoring consisted of convergence taping and optical survey target readings.
\end{abstract}

An interesting apparent anomaly in the monitoring data was noted between the $1 \mathrm{~mm}$ (only) settlement of the in tunnel crown and the up to $15 \mathrm{~mm}$ surface settlement (surface settlements were generally in the range of 5 to $8 \mathrm{~mm}$ ). Early strength measurements of the shotcrete were taken onsite and the next excavation cycle could not commence until a strength gain of 6 MPa was achieved.

The three railway tracks were monitored using three robotic scanning theodolites and the accuracy of the readings were very high as the prism targets were less than $50 \mathrm{~m}$ away from the monitoring stations. The survey prisms were fixed to the rails at $2 \mathrm{~m}$ intervals along all three railway tracks (400 prisms were used in total). The monitoring regime was important to ensure that the performance criteria for the track was not exceeded (no speed restrictions on passing trains were permitted other than in emergency situations, and none were imposed during tunnel construction), but also important given the shallow ground cover and that the primary tunnel support was a synthetic fibre reinforced shotcrete lining and any displacement could also be related to the strength and stiffness of the shotcrete, given that steel sets were not used.

The near real-time surface monitoring data and in tunnel monitoring data was reviewed at a daily construction site meeting and was used to confirm design assumptions and to justify either increasing or decreasing the tunnel excavation cycle length. Tunnel excavation was completed in late August 2014 with the track base slab and track and tunnel fit out followed in late 2014 and early 2015. The first freight trains will pass through the tunnel in June 2015.

\section{Introduction}

The North Strathfield Rail Underpass project (NSRU) is part of the Northern Sydney Freight Corridor (NSFC) Program, a joint Australian and NSW Government initiative to improve capacity and reliability of freight trains between Sydney and Newcastle. 
The NSRU project was delivered by an alliance between John Holland Group, Bouygues Construction Australia and Transport for NSW (TfNSW). The project grade separates freight trains entering Sydney from the north from the existing passenger railway lines and where in peak travel times the suburban network takes precedent over freight train movements.

A key feature of this project is the construction of a shallow driven tunnel beneath two existing operational commuter lines (up and down mains) and one freight railway line (down relief). Figure 1 below is a plan layout of the alignment.

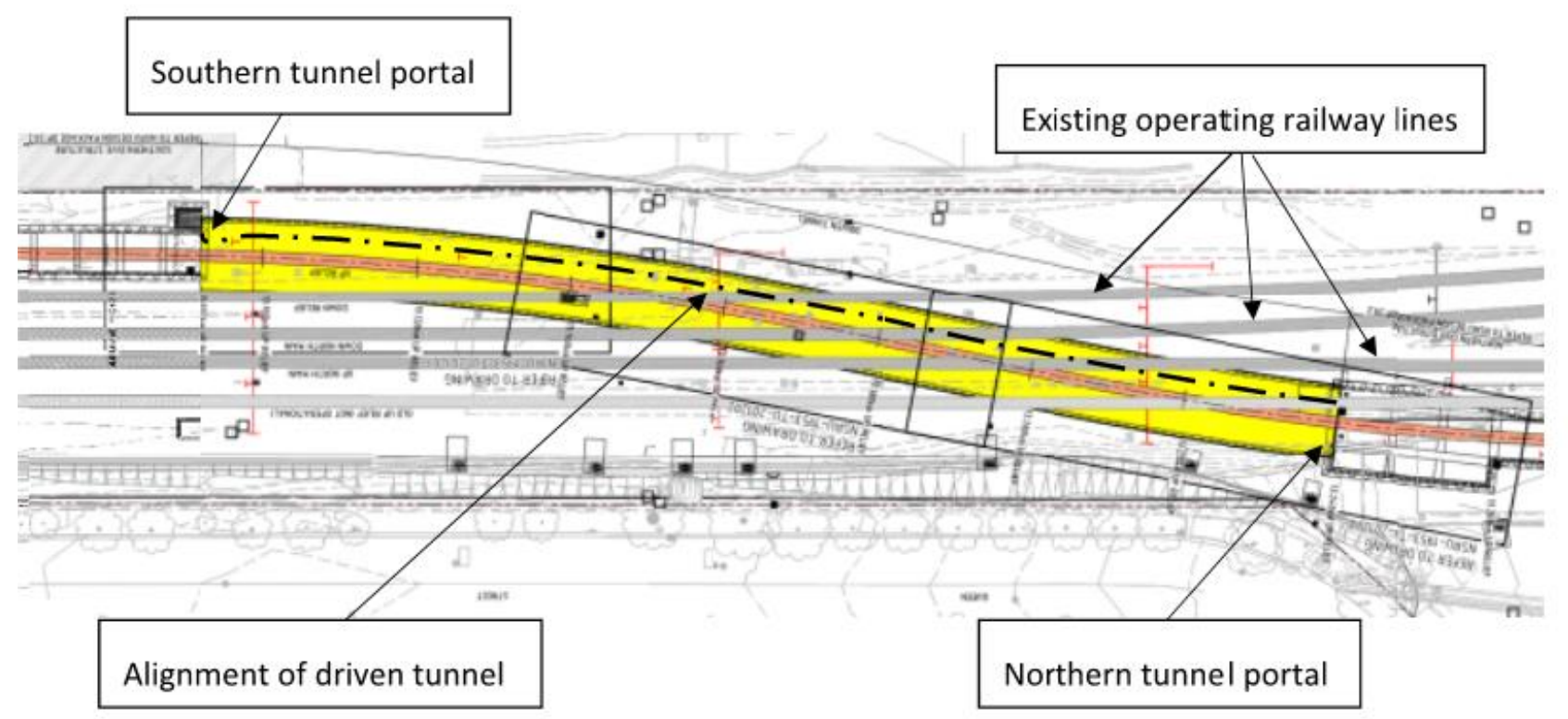

Figure 1 Plan of tunnel crossing beneath the existing operating railway lines

A previously considered construction option was a cut and cover tunnel; however, with only four weekend track possessions per year the construction period would have taken at least three years or possibly more. In contrast, it was possible to excavate the shallow cover tunnel under the live railway tracks in only eight months.

The tunnel was excavated from the north portal and is $148 \mathrm{~m}$ long. Further information about the project, in particular the driven tunnel, is provided by Nye (2015).

During the eight-month period taken to excavate the tunnel, 360 trains per day passed over the tunnel site that equates to 86,000 trains during this time frame and without any disruption to the Sydney suburban train network or to freight train operations.

\section{$2 \quad$ Project geotechnical investigations}

\subsection{Site investigation}

Site investigation boreholes and test pit excavations were carried out within the rail corridor track zone during the long weekend track possessions in June 2011 and September 2012.

Golders Associates carried out the site investigations on behalf of TfNSW with inputs from both the designers and their geotechnical consultant Douglas \& Partners. Additional boreholes that were not located in the rail danger zone were drilled outside track possessions.

The boreholes drilled on the track during the weekend possessions were drilled to a maximum depth of $11 \mathrm{~m}$ using a small tracked drilling rig. 
Visual inspection of the corridor during the June 2011 track possession revealed surface rock outcrops on the east embankments extending from the southern end of North Strathfield Railway Station up to the Pomeroy Street Road Bridge to the north. This was the prime factor leading to movement of the tunnel alignment northwards from the original cut and cover tunnel concept design location.

The site investigation failed to detect a dyke, which intersected the tunnel excavation. Though not of great consequence for this project, future seismic traverses should be considered as part of future site investigations within rail corridors.

\section{$2.2 \quad$ Geological model}

From the site investigation data, it was possible by interpolation to develop a geological long section and cross sections through the tunnel taken at $10 \mathrm{~m}$ intervals. Apart from the dyke that intersected the tunnel $60 \mathrm{~m}$ from the north portal and exited the tunnel at $90 \mathrm{~m}$ on the west wall, the geological interpretation was proven to be very accurate. The dyke when first intersected on the left hand side of the tunnel consisted of a medium strength rock which progressed with tunnel excavation advance to a stiff clay with a contrasting golden colour compared to the surrounding dark grey shale rock (Figure 2).

The typical face conditions consisted of extremely low, to low strength Ashfield Shale in the crown, low to medium strength shale down to the tunnel spring line and high strength shale in the lower half of the tunnel. Above the tunnel crown comprises residual clay, fill and ballast.

Test pits were also excavated between sleepers in critical locations along the track to determine the depths of the ballast and the ballast sub-base.

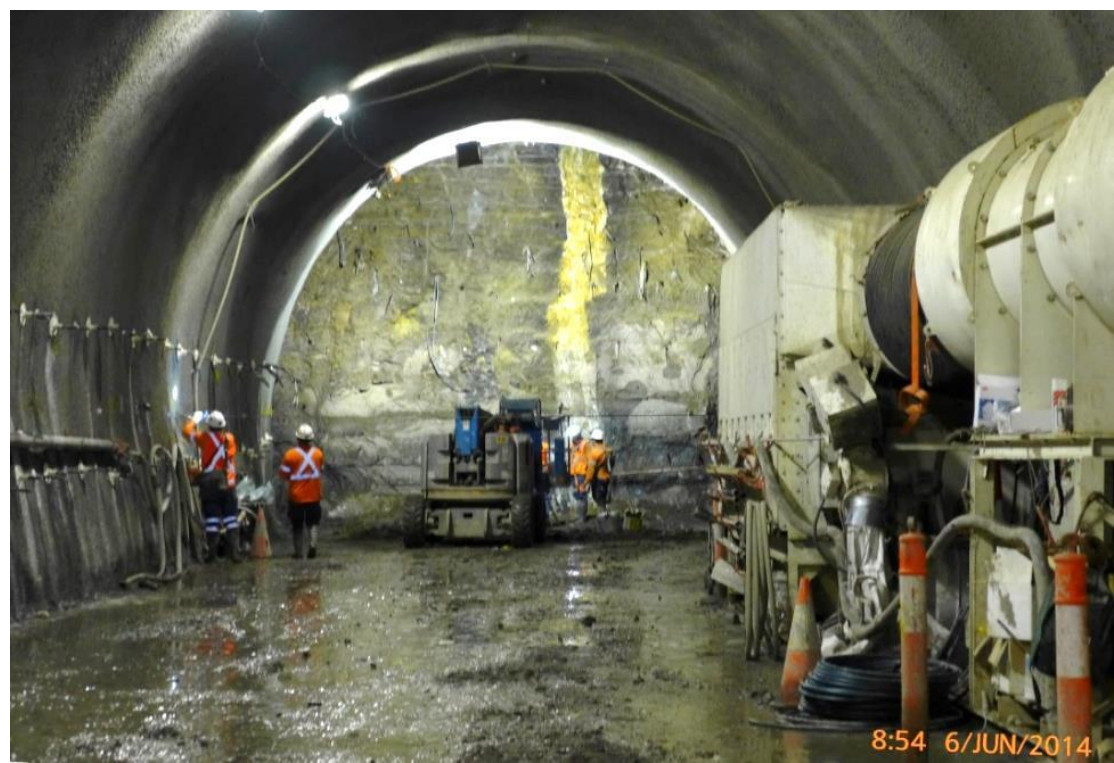

Figure 2800 mm wide dyke in tunnel face

\section{Tunnel design and construction}

\subsection{Construction}

The tunnel construction was by the drilling and placement of grout filled canopy tubes ahead of the advancing excavated face of the tunnel. The canopy tubes provide support to the tunnel crown during initial excavation and installation of structural shotcrete lining. The prevailing site conditions and rail environment requiring a slower rate of tunnel face advancement of between 1.0 and $1.5 \mathrm{~m}$ per day dependant on geology and the monitoring data and its interpretation.

For a driven tunnel where ground control was critical, the designers considered shotcrete to be the most appropriate tunnel support compared to say steel sets because it can be spayed directly onto the rock 
surface and provide full and intimate contact with the ground. This method is even more advantageous for full face tunnel excavation compared to the alternative of steel sets or lattice girders in such a large tunnel just for the construction simplicity alone.

The detailed design of the tunnel lining progressed on the basis of a synthetic fibre reinforced shotcrete. This form of tunnel lining used as primary and permanent support for a shallow tunnel is on a world basis quite unique in this type of application. The tunnel had to be constructed without disruption to the operating rail network above so that it was important that calculations by the designers could be verified on a continuous basis during construction so that adjustments to the shotcrete lining thickness or construction methodology could be made from timely and reliable information. Monitoring within the tunnel consisted of convergence taping, survey displacement prisms (in the tunnel crown and tunnel walls) as shown in Figure 3. The intensity of monitoring was increased to $1 \mathrm{~m}$ spacing (from $4 \mathrm{~m}$ spacing) along one section of tunnel where there was around $14 \mathrm{~mm}$ surface settlement but no measurable movements in the tunnel crown greater than around $1 \mathrm{~mm}$. The highest convergence at spring-line level between the tunnel side walls was around $3.5 \mathrm{~mm}$ and occurred where the tunnel first intersected the dyke at approximately $60 \mathrm{~m}$ from the north portal. Near real-time surface data from robotic scanning theodolites scanned the prism targets located on the track and additional surface targets on steel stakes pushed into the ground.

A full height heading excavation (rather than a heading and bench excavation) was used and provided a seamless $250 \mathrm{~mm}$ thick structural shotcrete lining over the full tunnel profile adding to its durability, lower permeability (no cold joint defects) and construction simplicity.

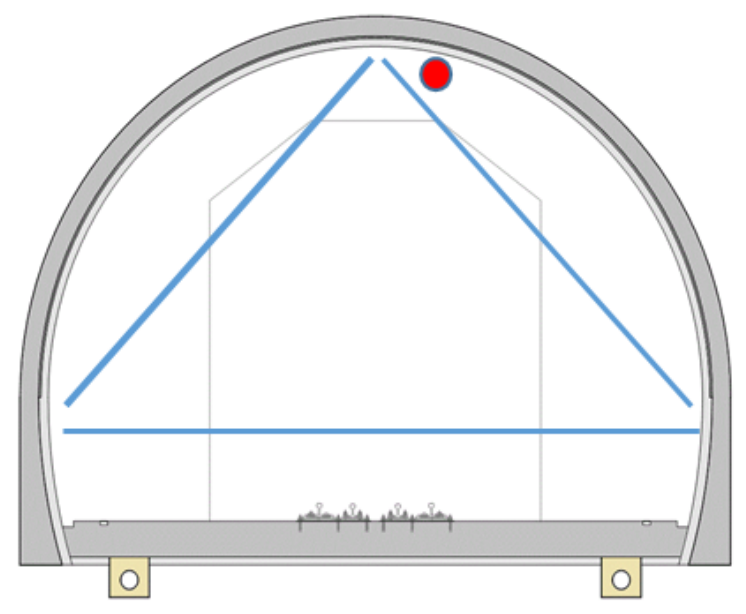

\section{Figure 3 Tunnel profile with a $250 \mathrm{~mm}$ thickness shotcrete lining (convergence tape (lines) and optical target (dot), in crown monitoring)}

It was anticipated from the FE analysis (which were conventional plain strain elastic analyses), case histories and previous recent project experience (Boggo Road Busway Tunnel, Brisbane) that the magnitude of surface settlement would be around $5 \mathrm{~mm}$, this was based on the assumption that each excavation cycle would be $1 \mathrm{~m}$ in length. During the construction phase, tunnel excavation commenced with $1.3 \mathrm{~m}$ excavation cycle lengths (based on better than expected ground conditions when initially exposed at the tunnel portal). Surface settlements observed before passing under the first live railway track were of the order of $6 \mathrm{~mm}$ (7 excavation cycles between canopy tube array installations which are $9 \mathrm{~m}$ apart, $12 \mathrm{~m}$ long canopy tubes with $3 \mathrm{~m}$ overlap). Through the daily permit to tunnel (PTT) process the excavation cycles were later increased to $1.5 \mathrm{~m}$. Excavation cycles were subsequently reduced to $1.3 \mathrm{~m}$, then back down to $1 \mathrm{~m}$ when a dyke, and associated poorer ground conditions, were intersected. Once this section was passed, excavation cycles went back up to $1.3 \mathrm{~m}$ cycle lengths and then, after finally passing all live track, back to $1.5 \mathrm{~m}$. 
The synthetic fibre shotcrete support within $3 \mathrm{~m}$ of the tunnel face had to achieve a minimum thickness of $250 \mathrm{~mm}$. The next excavation cycle could commence only after the initial $150 \mathrm{~mm}$ layer of shotcrete had reached $6 \mathrm{MPa}$.

\subsection{Structural shotcrete lining}

The tunnels circular arch profile over the tunnel crown was specifically developed by the designers to ensure that there was no flexure bending moments in the tunnel lining and that the applied loads were carried purely in compression.

The principle basis of the tunnel lining design and construction is that the shotcrete should be applied as close to the tunnel face as practical so that in effect, the ground does not have the opportunity to relax. The canopy tube array installed ahead of the excavation provides a short term semi rigid support of the ground at excavation and before the shotcrete lining application. The canopy tubes support allows the shotcrete lining time to cure and attain the required minimum strength before the next excavation cycle.

The maximum compressive stress in the shotcrete lining determined from FE analyses was a little under $4 \mathrm{MPa}$ (combined dead and live loading). For this reason, the shotcrete needed to gain an early strength value of at least $6 \mathrm{MPa}$ (early curing assisted by an accelerator in the shotcrete mix which is applied in the tunnel at the shotcrete spray applicator nozzle) before the next excavation cycle could commence. This strength level was achieved after about 7 hours. Onsite testing was carried out progressively at set time intervals, on small beam samples sprayed at the tunnel face, until the minimum strength value of $6 \mathrm{MPa}$ was attained.

Due to the 3D effect at the tunnel face, the full dead ground load is not fully active at the face, the live load due to the trains passing above, assuming no distribution of live load along the rail tracks, was around $50 \%$ of the total load. From our interpretation of the monitoring surface settlement data in conjunction with our modelling, full ground load appears to be applied between half and one full tunnel diameter back from the tunnel face at which point surface settlement would stop. The actual train live axial load is distributed through the stiff steel rail over at least 5 sleepers along the track. The sleepers are spaced $600 \mathrm{~mm}$ apart.

The shotcrete mix was developed through a number of iterations during the construction phase despite numerous shotcrete trials and testing having been carried out in the months prior to commencement of construction. For early strength gain, density and durability reasons a $40 \mathrm{MPa}$ mix was specified. The structural shotcrete had to have a design life of 100 years and as such, the shotcrete mix includes fly ash at $20 \%$ of cementitious content. The macro synthetic fibres used in the structural shotcrete were BarChip 60 with a dosage rate of $6 \mathrm{~kg} / \mathrm{m}^{3}$. The $100 \mathrm{~mm}$ fire protection shotcrete layer over the TamSeal 800 spray-on waterproofing membrane is the same mix design as the structural layer but with $6 \mathrm{~mm}$ long synthetic fibres designed to reduce explosive spalling and with a dosage rate of $2 \mathrm{~kg} / \mathrm{m}^{3}$.

Strength gain of site beam tested shotcrete (with fibres) is given in Table 1 together with the elastic modulus calculated using the following Australian Standard for concrete (Standards Australia 2009) formula given in Clause 3.1.2.

\section{Table 1 Summary of shotcrete strength gain with time}

\begin{tabular}{ccc}
\hline Time & Strength $(\mathrm{MPa})$ & Elastic modulus $(\mathrm{MPa})$ \\
\hline 7 hrs & 6 & 12,000 \\
1 day & 10 & 15,000 \\
3 days & 21 & 22,000 \\
7 days & 33 & 27,000 \\
28 days & 40 & 30,000 \\
\hline
\end{tabular}




$$
E_{c}=0.043 \rho^{1.5} \sqrt{f_{c}}
$$

where:

$$
\begin{aligned}
& E_{c} \quad=\text { modulus of elasticity in } \mathrm{MPa} . \\
& \rho \quad=\text { density of the concrete in } \mathrm{kg} / \mathrm{m}^{3} . \\
& f_{c} \quad=\text { compressive strength of concrete in MPa. }
\end{aligned}
$$

\section{$4 \quad$ Monitoring challenges}

\subsection{Overview}

Prevailing site conditions presented many challenges to the development of a realistic deformation monitoring process due to the following factors.

The fact that the tunnel was so shallow, causing vibration and track pumping, along with the construction and use of haul roads on either side of tunnelling operations (to the east and west) meant that there was no chance of installing geotechnical sensors such as borehole extensometers or inclinometers to allow a correlation of deformation measurements with total station readings.

Ballasted track is susceptible to apparent deformation whereby a train may occupy the track while a reading is being taken resulting in a limit exception and false alarm. The inconsistent passage of trains throughout the monitoring zone could not be controlled and thus a solution needed to be created to weed out readings where apparent deformation has occurred (see Section 4.3).

Track geometry was different on each rail line as the down relief line and the down main diverge to allow passage into the North Strathfield platform. This change in track geometry (i.e. no longer straight track) meant that cubic spiral transitions were now used within the deformation calculations resulting in different alarming criteria when using stakeholder maintenance specifications.

The narrow linear nature of the rail corridor added to the construction activities either side of the danger zone meant that two out of three monitoring stanchions were close to or within the zone of influence of the tunnel excavation. A secondary monitoring regime would need to be implemented to capture any deformation at these points and the observations corrected.

\subsection{Monitoring plan}

There is a distinct difference in the purpose of the surface track monitoring and the 'in tunnel' convergence monitoring. The primary purpose of the track monitoring is to protect the travelling public by ensuring that the rail tracks remained within relevant track specifications whereas the primary purpose of ground monitoring and convergence readings is to verify that the structural shotcrete lining of the tunnel was competent. These systems enabled the project to achieve the safety goal which was to cause no impact to the safety of the travelling public or construction team working below.

A comprehensive monitoring plan was developed for the tunnel that also included face mapping and a daily permit-to-tunnel (PTT) meeting between the designer, geotechnical engineer and the constructor. Often meetings also included the tunnel superintendents and the track certifier.

Deformation monitoring was the mechanism used to verify that the tunnel construction was being adequately controlled in accordance with allowable settlement limits and deformations. Within the tunnel, tape extensometer convergence observations and independent relative and absolute survey readings were taken as close to the tunnel face as was practical.

Prior to the commencement of tunnelling works on site, a baseline survey was undertaken of the track and surface marks. The existing condition of the track was monitored using both robotic survey methods with prisms spaced at $2 \mathrm{~m}$ intervals on both rails of each track and also by inspection and assessment by track certifiers. In all there were approximately 400 survey prisms used covering the three live tracks and ground 
stratum monitoring marks installed into capping material (until refusal) in between the live rail tracks and above the portals on either side.

The robotic survey data generated settlement plots that could be accessed offsite, saved and printed on any computer or hand held device (i.e. iPad and iPhone) connected to the internet.

\subsection{Track monitoring}

To ensure that tunnelling operations did not impact upon the integrity of existing track infrastructure, there was a need to operate within existing client maintenance specifications (RailCorp manual, Track Geometry and Stability (RailCorp 2013)) and that the system could measure to the same accuracy as that of a track certifiers cannot gauge.

The project monitoring system must also measure and alarm on the following four key rail variables:

- Long twist, measured over a baseline length of $14 \mathrm{~m}$ at $2 \mathrm{~m}$ stations.

- Short twist, measured over a $4 \mathrm{~m}$ baseline length at $2 \mathrm{~m}$ stations.

- Top, change in elevation measured over a $4 \mathrm{~m}$ baseline length at $2 \mathrm{~m}$ stations.

- Line, deviation of the track in plan over a baseline length of $8 \mathrm{~m}$ at $2 \mathrm{~m}$ stations.

In addition to this, any output was required to display the various readings against its relevant alarming criteria and provide a graphical display of those results. All of these four key rail variables must be measured across the entire zone of influence of the proposed tunnel, measuring some $200 \mathrm{~m}$ in length and involving the use of over 400 monitoring prisms (Figure 4).

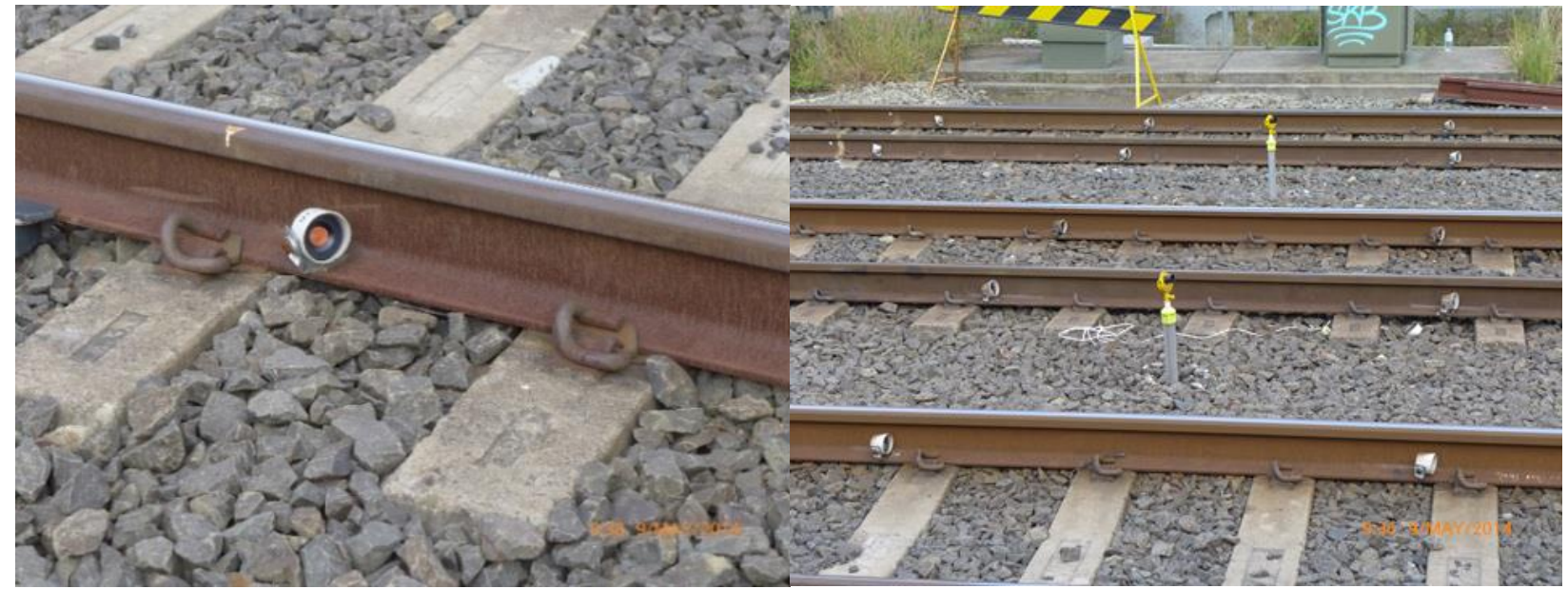

Figure 4 Leica GMP-104 single directional prism (mounted on foot of rail)

In November 2013, the NSRU commissioned the total station based Automated Deformation Monitoring System (ADMS) to measure 3D track deformation throughout the proposed tunnel construction phase. The ADMS consists of three robotic total station instruments used to measure in excess of 400 monitoring targets in real-time on a 24 hours a day, 7 days per week basis (typical settlement with time data plots are given in Figure 5).

Three monitoring stanchions exist (Figure 6) within this ADMS, each with two separate total station mount points, associated communications, mains power and UPS capabilities. The additional mount point at each location enabled the Alliance to instantly double the monitoring frequency should circumstance require it.

Monitoring Stanchions were also positioned in such a way as to minimise the length of the required range measurement, i.e. from total station to monitoring prism and hence to minimise the parts per million (PPM) error values associated with all EDM measurements. 
An added feature of the ADMS is that the total station mount points have been elevated to $3.5 \mathrm{~m}$ above nominal ground level improving the collection of data from the theodolite and deterring vandalism.

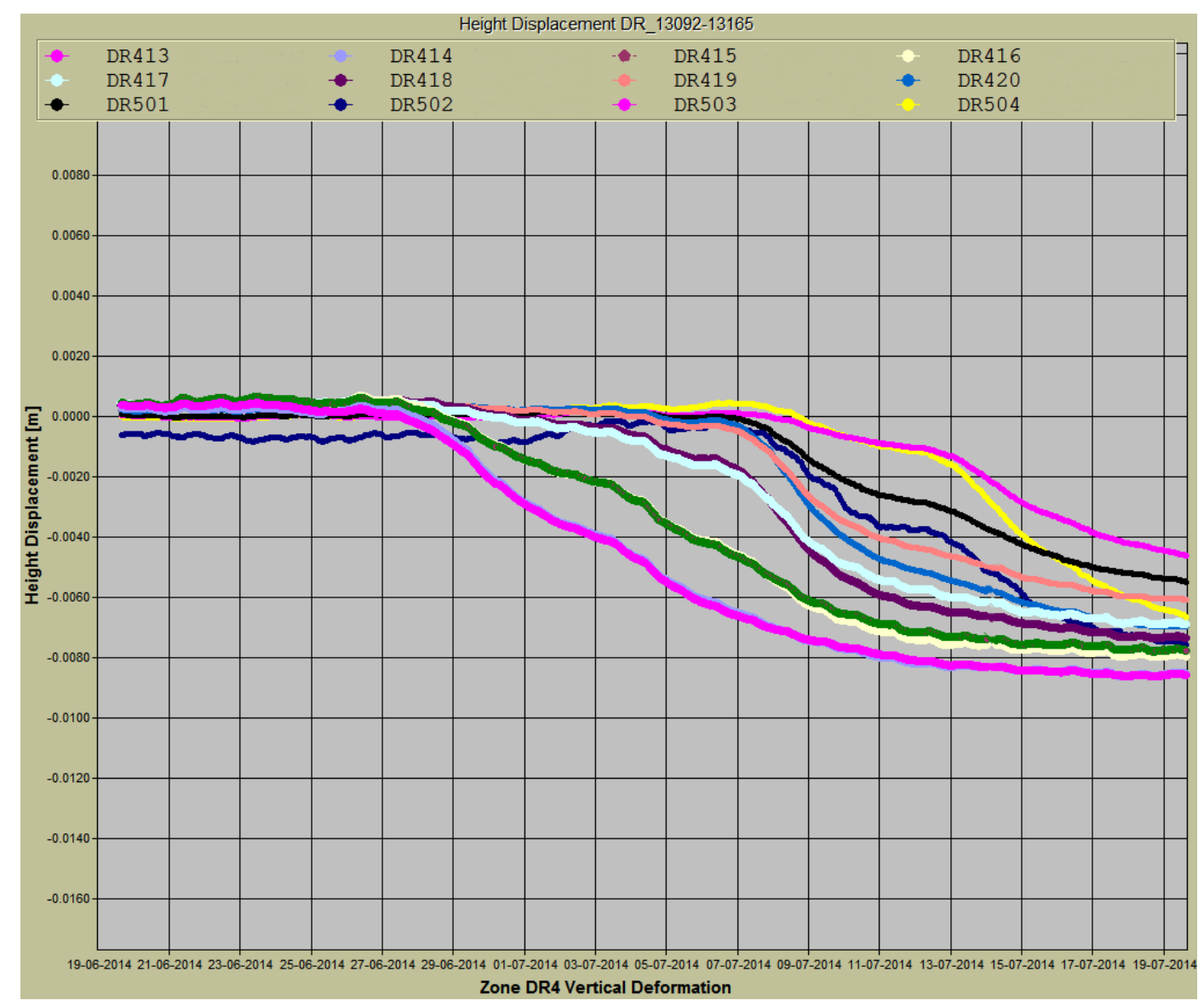

Figure 5 Typical settlement plot track monitoring (screen capture)

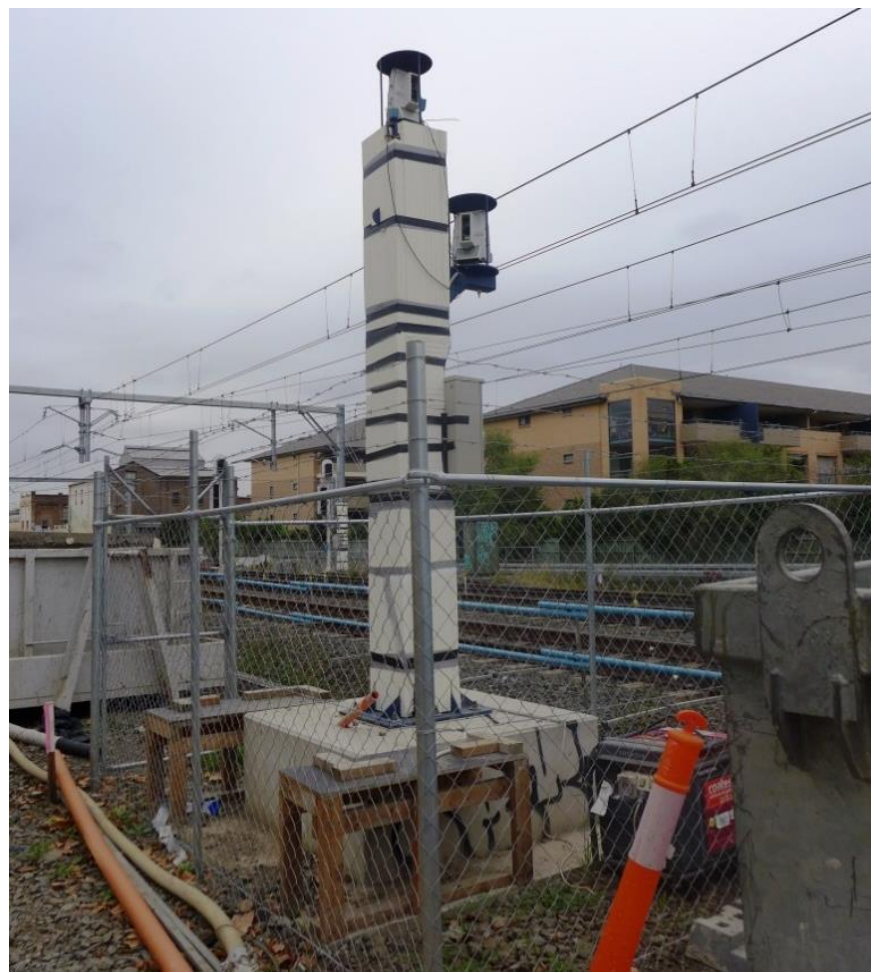

Figure 6 Purpose built monitoring stanchion (with dual mount points) 


\subsection{Development and use of real-time and rolling average alarming concepts}

The four rail parameters required by the stakeholder (short and long twist, top and line) are all relative measurements, that is, that they rely on a comparison with one or more other measurements in order to be calculated. This requires the collection of measurements until such time as a relative comparison can be made, then to calculate and report those values. This, however, is not a real-time system.

Through consultation with stakeholders, it was decided that a dual system of reporting could be developed and used. The dual system was comprised of a single point deformation monitoring, reporting and alarming in real-time, and a 'rolling average' alarming and reporting system that would collect measurements across a specified time frame, i.e. readings taken four times per hour, averaged and used for the required calculations, current values of the four key parameters derived and reported/alarmed accordingly.

Through the use of both real-time and rolling average alarming, the project was able to meet stakeholder requirements and significantly minimise the effect of apparent deformation.

\subsection{Surface monitoring zones}

Each of the three rail tracks were broken down into $20 \mathrm{~m}$ long zones comprising of ten targets (at $2 \mathrm{~m}$ spacing on each rail) for the purposes of referencing and reporting.

\subsection{Linkage of zones to construction activities}

By linking measurement zones to construction activities, it was possible to concentrate measurements in areas where they were required most. The area of most interest will be those areas centred on the advancing tunnel face, as well as just in front and behind it.

It was agreed with stakeholders that the alarming for any particular zone could be turned on or off relative to whether the tunnel had any influence over deformation. Those zones turned 'off' would then be monitored less frequently.

The most suitable linkage to construction activities in this tunnel is the drilling and insertion of canopy tubes (Figure 7) around the tunnel crown as this precedes any noticeable deformation.

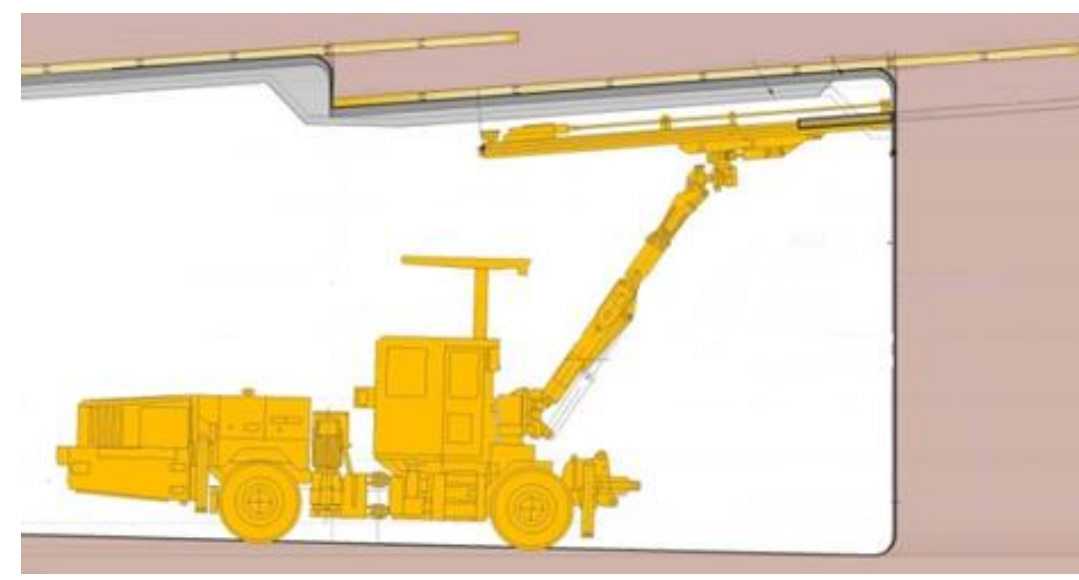

Figure 7 Drilling and Installation of canopy tubes ( $2.5 \mathrm{~m}$ below railway tracks)

\subsection{Calculation and reporting software}

Leica GeoMOS was used as the software platform to collect store and report deformation readings. GeoMOS is a commercially available software package that forms the measurement engine of the monitoring system. This software has the ability to:

- Remotely control measurement sensors such as theodolites and extensometers.

- Create measurement points and group them. 
- Program measurement sequences.

- Calculate deviations in level and longitudinal/transverse relative to straight user defined alignments.

- Raise alarms based upon a deformation limit or measurement variable (such as tilt error).

The GeoMos Monitor software is the front end application supported at the back end by a Microsoft SQL relational database management system. This means that SQL queries can be created in order to output data from the data base. Figure 8 shows a typical project output plot to stakeholder specifications. This technique of data processing was pioneered by Leica Geosystems representative, Mr Neil Ashcroft.

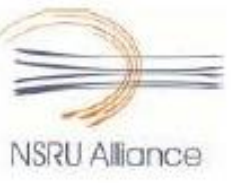

\section{NSRU - Track Report : D_Track}

\section{Start Time : 2014-08-22 12:00:00}

End Time : 2014-08-22 14:00:00

\begin{tabular}{|c|c|c|c|c|c|c|c|c|c|c|c|c|c|c|c|}
\hline \multirow[b]{2}{*}{$\begin{array}{c}\text { Chainage } \\
\text { (m) }\end{array}$} & \multirow[b]{2}{*}{ Zone } & \multicolumn{5}{|c|}{ Left Rail } & \multicolumn{5}{|c|}{ Right Rail } & \multirow[b]{2}{*}{$\begin{array}{c}\text { Gauge } \\
\text { (m) }\end{array}$} & \multirow[b]{2}{*}{\begin{tabular}{|l|} 
Cant \\
$(\mathrm{mm})$
\end{tabular}} & \multirow[b]{2}{*}{$\begin{array}{c}\text { Short Twist } \\
\text { (mm) }\end{array}$} & \multirow[b]{2}{*}{$\begin{array}{l}\text { Long Twist } \\
\text { (mm) }\end{array}$} \\
\hline & & ID & \begin{tabular}{|c|} 
dLevel \\
$(\mathrm{mm})$
\end{tabular} & $\begin{array}{c}\text { Top (4m) } \\
(\mathrm{mm})\end{array}$ & $\begin{array}{l}\text { dLine } \\
(\mathrm{mm})\end{array}$ & $\begin{array}{c}\text { Line }(8 \mathrm{~m}) \\
(\mathrm{mm})\end{array}$ & ID & \begin{tabular}{|l|} 
dLevel \\
$(\mathrm{mm})$
\end{tabular} & $\begin{array}{c}\text { Top }(4 \mathrm{~m}) \\
(\mathrm{mm})\end{array}$ & $\begin{array}{l}\text { dLine } \\
(\mathrm{min})\end{array}$ & $\begin{array}{c}\text { Line }(8 \mathrm{~m}) \\
(\mathrm{mm})\end{array}$ & & & & \\
\hline 13114.00 & ZoneD6 & D620 & 1.0 & (1.5) & (3.6) & 0.6 & D619 & 0.4 & $(0.5)$ & (3.7) & \begin{tabular}{|l|}
0.9 \\
\end{tabular} & 1.438 & 0.5 & $(0.1)$ & $\mathrm{NaN}$ \\
\hline 13116.10 & ZoneD6 & D618 & 0.9 & $(0.7)$ & (3.9) & 1.2 & D617 & 0.5 & $(0.8)$ & (3.3) & 1.4 & 1.439 & 2.5 & 2.0 & $\mathrm{NaN}$ \\
\hline 13118.10 & ZoneD6 & D616 & 0.5 & 0.2 & (3.8) & 0.2 & D615 & 0.4 & $(0.7)$ & (3.7) & $(0.4)$ & 1.442 & 4.2 & 1.7 & $\mathrm{NaN}$ \\
\hline 13120.00 & ZoneD6 & D614 & 0.5 & $\overline{(2.0)}$ & (3.8) & \begin{tabular}{|c|}
$(0.3)$ \\
\end{tabular} & D613 & 0.3 & (2.6) & (3.6) & 0.3 & 1.440 & |4.1 & \begin{tabular}{|c|}
$(0.1)$ \\
\end{tabular} & $\mathrm{NaN}$ \\
\hline 13121.90 & ZoneD6 & D612 & $(0.2)$ & $(2.3)$ & $(4.0)$ & $(0.1)$ & D611 & 0.2 & (3.4) & (3.9) & $(0.4)$ & 1.439 & 2.6 & (1.5) & 4.8 \\
\hline 13124.20 & ZoneD6 & D610 & $(0.7)$ & 0.3 & (4.3) & 0.2 & D609 & (1.2) & 3.5 & (3.8) & 0.2 & 1.438 & (1.1) & (3.7) & (1.1) \\
\hline 13126.00 & ZoneD6 & D608 & (1.7) & 2.9 & $(4.3)$ & $(0.2)$ & D607 & $(0.9)$ & 4.0 & (4.3) & $(0.2)$ & 1.439 & 1.5 & 2.6 & 0.9 \\
\hline 13128.00 & ZoneD6 & D606 & (1.8) & $(1.3)$ & $(4.4)$ & $(0.2)$ & D605 & (0.7) & (3.9) & (4.3) & 0.3 & 1.439 & 6.4 & 4.9 & 5.9 \\
\hline 13129.90 & ZoneD6 & D604 & $(2.0)$ & 0.5 & $(4.8)$ & 1.3 & D603 & $(0.3)$ & $(0.2)$ & $(4.6)$ & 0.9 & 1.440 & 6.0 & $(0.4)$ & 3.5 \\
\hline 13132.10 & ZoneD6 & D602 & $(2.5)$ & $(0.4)$ & (4.9) & $(0.9)$ & D601 & $(0.1)$ & 0.1 & (4.6) & 0.5 & 1.438 & 4.1 & (1.9) & $(0.1)$ \\
\hline 13134.10 & ZoneD5 & D520 & (2.4) & $(1.1)$ & (3.4) & (1.3) & D519 & (1.1) & $(0.6)$ & (3.5) & $(0.9)$ & 1.439 & 3.2 & $(0.9)$ & $(0.9)$ \\
\hline 13136.00 & ZoneD5 & D518 & (2.5) & (1.1) & (4.2) & (1.8) & D517 & (2.1) & $(0.7)$ & (3.9) & $(1.3)$ & 1.442 & 3.4 & 0.2 & 0.8 \\
\hline 13137.90 & ZoneD5 & D516 & (3.4) & 1.7 & $(4.6)$ & 0.5 & D515 & (1.9) & 0.3 & $(4.3)$ & $(0.5)$ & 1.442 & 4.4 & 1.0 & 5.5 \\
\hline 13140.00 & ZoneD5 & D514 & (4.3) & 0.7 & (5.9) & 0.6 & D513 & (2.6) & 1.7 & $(5.3)$ & 0.4 & 1.437 & 2.8 & (1.6) & 1.3 \\
\hline 13142.00 & ZoneD5 & D512 & (5.3) & $(1.7)$ & (6.1) & 1.1 & D511 & (2.3) & $(1.8)$ & $(6.1)$ & 1.3 & 1.438 & 3.0 & 0.2 & $\overline{(3.4)}$ \\
\hline 13143.90 & ZoneD5 & D510 & (5.6) & $(0.7)$ & $(6.2)$ & 1.2 & D509 & (2.5) & 0.5 & $(6.3)$ & 1.7 & 1.438 & 3.1 & 0.1 & (2.9) \\
\hline 13145.80 & ZoneD5 & D508 & $(6.2)$ & $(0.1)$ & $(5.5)$ & 1.0 & D507 & (3.8) & (1.6) & $(5.4)$ & 1.2 & 1.439 & 5.4 & 2.3 & 1.3 \\
\hline 13148.00 & ZoneD5 & D506 & (6.6) & 2.8 & $(4.1)$ & 0.3 & D505 & (4.8) & 2.1 & $(4.0)$ & $(0.4)$ & 1.440 & 4.8 & $(0.6)$ & $\overline{1.6}$ \\
\hline 13150.10 & ZoneD5 & D504 & $(6.9)$ & 3.5 & $(3.0)$ & $(0.4)$ & D503 & $(5.0)$ & 3.5 & (2.3) & $(0.8)$ & 1.439 & 2.9 & (1.9) & $(0.5)$ \\
\hline 13152.10 & ZoneD5 & D502 & $(6.3)$ & 1.3 & $(2.2)$ & (1.5) & D501 & (5.2) & 0.7 & (1.5) & $(2.0)$ & 1.440 & 1.1 & $(1.8)$ & (3.3) \\
\hline
\end{tabular}

\section{Tolerances}

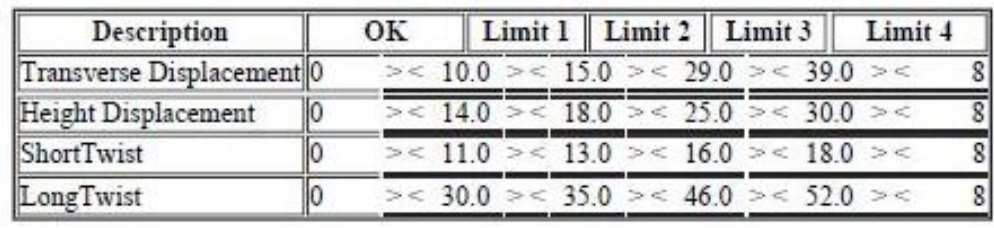

Figure 8 Typical output from track report 


\subsection{In tunnel monitoring}

The 'in tunnel' monitoring component was completed using a traditional three-point convergence configuration and optical target in the tunnel crown (Figure 3).

Two methods of convergence measurement were adopted by the project, firstly direct measurements using a highly accurate steel tape were observed between convergence marks placed in the tunnels structural lining (see Figure 5 ) and secondly, total station methods were employed to read relative convergence and absolute $X, Y, Z$ readings on independent convergence markers.

Due to the fact that in tunnel convergence marks are not physically able to be installed until the primary shotcrete support is installed and has reached its minimum required strength, only very small deformation readings were recorded. One possible explanation is that some of the settlement may have already occurred although the readings were of such a small magnitude this does not fully explain this observation.

Another explanation of the higher surface settlements of the surface compared to in tunnel deformations is that of ground consolidation of the fill and residual soil above the tunnel crown, probably due to a combination of changes to the groundwater table combined with the live loading of the passing trains (train axial design loads of 30 tonne on freight trains). The dyke zone actually formed a water barrier across the tunnel which was observed as a difference in water table levels either side of the dyke. Further interpretation of the site data monitoring data and construction progress is required at this stage to be able to provide a more conclusion explanation than those already suggested above.

\section{$5 \quad$ Recommendations and conclusion}

Without a comprehensive monitoring plan and its execution including both the surface railway track (in near real-time) and in tunnel displacement monitoring it would not have been possible to foresee the innovative tunnel construction method being adopted under live train operations for such a shallow cover tunnel as used on this project.

Remote access at all times to railway track data also proved invaluable, more so given that tunnel excavation was also a 7 days a week, 24 hours a day activity. Data access was available through any internet connected device (iPhone, iPad or computer).

All of the data was reviewed formally at a daily Permit to Tunnel meeting. Reliable timely data not only confirmed design assumptions but also allowed the tunnel excavation cycle length to be altered (increased or decreased) based on ground conditions and the displacement monitoring data's trends and magnitudes. It is clear that other parameters, like the early strength gain of the tunnel shotcrete lining and geological face mapping, were also assessed at these meetings.

Given the shallow cover above the tunnel of only $3 \mathrm{~m}$ limiting surface settlement to just $15 \mathrm{~mm}$ and not disrupting train operations was a significant achievement. The maximum recorded settlement was around $15 \mathrm{~mm}$. The excavation cycle lengths varied and were $1,1.3$ or $1.5 \mathrm{~m}$. When a dyke was intersected settlements increased and this was also associated with more soft ground in the tunnel crown. The excavation cycle length was progressively reduced to $1 \mathrm{~m}$ through this zone including installing additional face dowels.

Although surface settlements were of the order of 6 to $15 \mathrm{~mm}$ this was not reflected in movement of the tunnel crown within the tunnel. Initial readings being taken very close to the tunnel face with maximum crown settlements $10 \mathrm{~m}$ or more back along the tunnel were never greater than $1 \mathrm{~mm}$. Readings taken in the crown at close intervals of $1 \mathrm{~m}$ were consistently giving the same results.

During the planning phase, downhole canopy tube deformation measurements were considered in order to obtain reliable initial baseline reading ahead of the tunnel excavation (and canopy tube deflections). This approach was, however, discounted because of the cost and doubts about the reliability of such systems. In the opinion of the authors, more development is required in this area of monitoring for it to be widely adopted for use in a commercial and harsh environment such as tunnelling. 
Given the tunnel excavation width was $9 \mathrm{~m}$, the convergence of the tunnel walls of only a few millimetres was very small, but consistent with the FE analysis predictions. Where a dyke intersected the tunnel through a side wall at 15 degrees to the tunnel alignment convergence increased to a maximum of $3.5 \mathrm{~mm}$. Permanent fibreglass dowels were installed through the tunnel walls to stich the strata together as a precaution. These fully grouted dowels were up to $8 \mathrm{~m}$ in length.

\section{Acknowledgement}

Sinclair Knight Merz (now Jacobs Engineering) and Parsons Brinkerhoff were the lead JV design consultants for the NSRU project. Mott MacDonald Australia developed the driven tunnel concept, provided the detailed designs and construction methodology and were engaged on a daily basis with the construction team monitoring of the tunnel construction. The Alliance members were John Holland, Bouygues and Transport for NSW.

\section{References}

Nye, T 2015, 'A one pass synthetic fibre reinforced shotcrete tunnel lining for a very shallow cover tunnel, North Strathfield Rail Underpass', in MC Johnson \& S Oginski (eds), Proceedings of the Rapid Excavation and Tunnelling Conference (RETC 2015), Society for Mining, Metallurgy \& Exploration, Englewood, CO.

RailCorp 2013, TMC 211 - track geometry \& stability: engineering manual, version 4.8, RailCorp, Chippendale, viewed 1 June 2015 , http://www.asa.transport.nsw.gov.au/sites/default/files/asa/railcorp-legacy/disciplines/civil/tmc-211.pdf

Standards Australia 2009, Australian Standard ASS3600: Concrete Structures, Standards Australia, Sydney. 